\title{
FOUR DIMENSIONAL CIRCULAR MODEL TO MEASURE INTERACTION OF TWO ECONOMIES
}

\author{
Author: Asli Pinar Tan ${ }^{\S}$
}

\begin{abstract}
In the book "Everyhing Is A Circle: A New Model For Orbits Of Bodies In The Universe", and further in the Article "Distance Between Two Circles in Any Number of Dimensions is a Vector Ellipse", it has been mathematically demonstrated that "distance between points on any two different circles in any number of multiple dimensions" is equivalent to "distance of points on a vector ellipse from another fixed or moving point”. Using this mathematical methodology, a method is provided in this Article as a measure for the amount of interaction between two international economies, which are two countries or economic zones, by modelling each economy in terms of a "circle in four dimensions". Based on this method, the proximity of the two economies at the end of each fiscal period, which is generally a fiscal year, is then measured by the distance between points at the end of the given period on the two circles in four dimensions, associated with these two economies in our model.
\end{abstract}

\begin{abstract}
ARTICLE
Gross National Income (GNI) ${ }^{1}$ is a country's total domestic and foreign income claimed by its residents during in a fiscal period, consisting of Gross Domestic Product (GDP) ${ }^{2}$ plus net receipts of income from abroad.

Gross Domestic Product (GDP) ${ }^{2}$ is the measure of income earned through the production of goods and services in a country during a fiscal period, or equivalently the total amount spent on goods and services less imports.

"GNI per capita" ${ }^{3}$ is a country's final income in a fiscal period, divided by its population.

In the book "Everyhing Is A Circle: A New Model For Orbits Of Bodies In The Universe"4, and further in the Article "Distance Between Two Circles in Any Number of Dimensions is a Vector
\end{abstract}

\footnotetext{
$\S$ Author: Aslı Pınar Tan

LinkedIn Website: http://www.linkedin.com/in/apinartan

E-mail: aslipinartan@superonline.com
} 
Ellipse", it has been mathematically demonstrated that "distance between points on any two different circles in any number of multiple dimensions" is equivalent to "distance of points on a vector ellipse ${ }^{6}$ from another fixed or moving point". Using this mathematical methodology, in this Article we aim to provide a measure for the amount of interaction between two international economies, in other words between two countries or economic zones, by modelling each economy in terms of a "circle in four dimensions". The proximity of the two economies at the end of each fiscal period, which is generally a fiscal year, can then be measured by the distance between points at the end of the given period on the two circles in four dimensions, corresponding to these two economies in our model.

As a background, consider a system of two circles in four-dimensions defined in terms of perpendicular coordinates $\left(\hat{\boldsymbol{u}}_{1}, \hat{\boldsymbol{u}}_{2}, \hat{\boldsymbol{u}}_{3}, \hat{\boldsymbol{u}}_{4}\right)$.

The phases $\phi_{1}(t)$ (2) and $\phi_{2}(t)$ (3), respectively, of points $\mathbf{P}_{1}$ and $\mathbf{P}_{2}$ on these two circles, moving as a function of time $t$ with respect to the centers of their own circles, and their phase difference $\phi_{0}(t)$ (4), is expressed in (2) - (4), with the moving points $\mathbf{P}_{1}$ and $\mathbf{P}_{2}$ phased with fixed but different (1) angular velocities $\omega_{1}$ (2) and $\omega_{2}$ (3), respectively, with respect to the centers of their own circles of revolution, their phase difference being $\left[\phi_{0}\left(t_{0}\right)=0\right]$ (4) at time $\left(t=t_{0}=0\right)$, the reference timestamp $t_{0}$ taken to be the point in time when points $\mathbf{P}_{1}$ and $\mathbf{P}_{2}$ have a phase of $\left[\phi_{1}\left(t_{0}\right)=\phi_{2}\left(t_{0}\right)=0\right]$ (2) - (3) simultaneously.

$$
\begin{gathered}
\omega_{1} \neq \omega_{2} \quad\left(\omega_{1} \& \omega_{2} \text { constant }\right) \\
\left.\phi_{1}(t)=\phi+\phi_{0}=\phi(t)+\phi_{0}(t)=\phi_{2}(t)+\phi_{0}(t)=\omega_{1} t ; \phi_{1}\left(t_{0}=0\right)=0 \quad \text { (Phase of } \mathbf{P}_{1}\right) \\
\phi_{2}(t)=\phi=\phi(t)=\omega_{2} t \quad ; \quad \phi_{2}\left(t_{0}=0\right)=0 \quad\left(\text { Phase of } \mathbf{P}_{2}\right) \\
\left.\phi_{0}(t)=\phi_{1}(t)-\phi_{2}(t)=\left(\omega_{1}-\omega_{2}\right) t \quad ; \quad \phi_{0}\left(t_{0}=0\right)=0 \quad ; \quad \text { (Phase difference of } \mathbf{P}_{1} \text { and } \mathbf{P}_{2}\right)
\end{gathered}
$$

The two circles can be defined in the simplest case to have vector radii $\vec{r}_{1}(5)-(6)$ and $\vec{r}_{2}(7)$, with constant magnitudes $r_{1}(8)$ and $r_{2}(8)$, respectively, which are radius vectors at point $\mathbf{P}_{1}$ phased at $\left(\phi+\phi_{0}\right)$ (2) and $\mathbf{P}_{2}$ phased at $\phi$ (3) on the two circles, respectively, phased apart by a 
time $(t)$-dependent angle $\phi_{0}$ (4). Note that $\beta_{1}(5)-(6)$ is taken to be the constant inclination angle between these two circles in the $\hat{\boldsymbol{u}}_{1}-\hat{\boldsymbol{u}}_{3}$ dimension plane, and $\beta_{2}(5)-(6)$ is taken to be the constant inclination angle between these two circles in the $\hat{\boldsymbol{u}}_{2}-\hat{\boldsymbol{u}}_{4}$ dimension plane.

$$
\begin{aligned}
& \overrightarrow{\boldsymbol{r}}_{1}=\overrightarrow{\boldsymbol{r}}_{1}\left(\phi+\phi_{0}\right)=\hat{\boldsymbol{u}}_{1} r_{1} \operatorname{Cos}\left(\phi+\phi_{0}\right) \operatorname{Cos} \beta_{1}+\hat{\boldsymbol{u}}_{2} r_{1} \operatorname{Sin}\left(\phi+\phi_{0}\right) \operatorname{Cos} \beta_{2} \\
& +\hat{\boldsymbol{u}}_{3} r_{1} \operatorname{Cos}\left(\phi+\phi_{0}\right) \operatorname{Sin} \beta_{1}+\hat{\boldsymbol{u}}_{4} r_{1} \operatorname{Sin}\left(\phi+\phi_{0}\right) \operatorname{Sin} \beta_{2} \\
& \overrightarrow{\boldsymbol{r}}_{1}=\overrightarrow{\boldsymbol{r}}_{1}(\phi)=\left(\hat{\boldsymbol{u}}_{1} r_{1} \operatorname{Cos} \beta_{1} \operatorname{Cos} \phi_{0}+\hat{\boldsymbol{u}}_{2} r_{1} \operatorname{Cos} \beta_{2} \operatorname{Sin} \phi_{0}+\hat{\boldsymbol{u}}_{3} r_{1} \operatorname{Sin} \beta_{1} \operatorname{Cos} \phi_{0}+\hat{\boldsymbol{u}}_{4} r_{1} \operatorname{Sin} \beta_{2} \operatorname{Sin} \phi_{0}\right) \operatorname{Cos} \phi+ \\
& \left(-\hat{\boldsymbol{u}}_{1} r_{1} \operatorname{Cos} \beta_{1} \operatorname{Sin} \phi_{0}+\hat{\boldsymbol{u}}_{2} r_{1} \operatorname{Cos} \beta_{2} \operatorname{Cos} \phi_{0}-\hat{\boldsymbol{u}}_{3} r_{1} \operatorname{Sin} \beta_{1} \operatorname{Sin} \phi_{0}+\hat{\boldsymbol{u}}_{4} r_{1} \operatorname{Sin} \beta_{2} \operatorname{Cos} \phi_{0}\right) \operatorname{Sin} \phi \\
& \overrightarrow{\boldsymbol{r}}_{2}=\overrightarrow{\boldsymbol{r}}_{2}(\phi)=\hat{\boldsymbol{u}}_{1} r_{2} \operatorname{Cos} \phi+\hat{\boldsymbol{u}}_{2} r_{2} \operatorname{Sin} \phi \\
& \overrightarrow{\boldsymbol{r}}_{1} \cdot \overrightarrow{\boldsymbol{r}}_{1}=r_{1}^{2} \quad ; \quad\left|\overrightarrow{\boldsymbol{r}}_{1}\right|=r_{1}=\sqrt{\overrightarrow{\boldsymbol{r}}_{1} \cdot \overrightarrow{\boldsymbol{r}}_{1}} \quad ; \quad \overrightarrow{\boldsymbol{r}}_{2} \cdot \overrightarrow{\boldsymbol{r}}_{2}=r_{2}^{2} \quad ; \quad\left|\overrightarrow{\boldsymbol{r}}_{2}\right|=r_{2}=\sqrt{\overrightarrow{\boldsymbol{r}}_{2} \cdot \overrightarrow{\boldsymbol{r}}_{2}}
\end{aligned}
$$

The centers of these two circles in four-dimensions are displaced by a constant vector $\vec{\ell}$ (9) with magnitude $\ell(10)$ at each phase $\phi$, defined in terms of perpendicular coordinates $\left(\hat{\boldsymbol{u}}_{1}, \hat{\boldsymbol{u}}_{2}, \hat{\boldsymbol{u}}_{3}, \hat{\boldsymbol{u}}_{4}\right)$.

$$
\begin{gathered}
\vec{\ell}=\hat{\boldsymbol{u}}_{1} \ell_{u_{1}}+\hat{\boldsymbol{u}}_{2} \ell_{u_{2}}+\hat{\boldsymbol{u}}_{3} \ell_{u_{3}}+\hat{\boldsymbol{u}}_{4} \ell_{u_{4}} \\
|\vec{\ell}|=\ell=\sqrt{\vec{\ell} \cdot \vec{\ell}} ; \quad \ell^{2}=\vec{\ell} \cdot \vec{\ell}=\ell_{u_{1}}^{2}+\ell_{u_{2}}^{2}+\ell_{u_{3}}^{2}+\ell_{u_{4}}^{2}
\end{gathered}
$$

As demonstrated in the Article "Distance Between Two Circles in Any Number of Dimensions is a Vector Ellipse" ${ }^{, 5}$, the vector distance between points $\mathbf{P}_{1}$ phased at $\left(\phi+\phi_{0}\right)$ (2) and $\mathbf{P}_{2}$ phased at $\phi$ (3) on the two respective circles in four dimensions, at any value of the phase $\phi$ (3), can be equivalently expressed as $\overrightarrow{\boldsymbol{d}}(\phi)$ (11) in terms of vectors $\overrightarrow{\boldsymbol{a}}$ (12) and $\overrightarrow{\boldsymbol{b}}$ (13), which turn out to be the semi-major ${ }^{7}$ and semi-minor ${ }^{7}$ axis vectors of the vector ellipse $e^{6}$ that is virtually formed between the two circles in four-dimensions, defined utilizing $\vec{r}_{1}$ (5) - (6) and $\vec{r}_{2}$ (7), with magnitudes $a(14)$ and $b(15)$, respectively, and $\operatorname{Dot}_{\operatorname{Product}}^{8}(\overrightarrow{\boldsymbol{a}} \cdot \overrightarrow{\boldsymbol{b}})(16)$.

$$
\begin{gathered}
\overrightarrow{\boldsymbol{d}}(\phi)=\overrightarrow{\boldsymbol{r}_{1}}(\phi)-\overrightarrow{\boldsymbol{r}_{2}}(\phi)+\vec{\ell} \quad \text { where } \quad \overrightarrow{\boldsymbol{r}}_{1}(\phi)-\overrightarrow{\boldsymbol{r}_{2}}(\phi)=\overrightarrow{\boldsymbol{a}} \operatorname{Cos} \phi+\overrightarrow{\boldsymbol{b}} \operatorname{Sin} \phi \\
\overrightarrow{\boldsymbol{a}}=\hat{\boldsymbol{u}}_{1}\left(r_{1} \operatorname{Cos} \beta_{1} \operatorname{Cos} \phi_{0}-r_{2}\right)+\hat{\boldsymbol{u}}_{2} r_{1} \operatorname{Cos} \beta_{2} \operatorname{Sin} \phi_{0}+\hat{\boldsymbol{u}}_{3} r_{1} \operatorname{Sin} \beta_{1} \operatorname{Cos} \phi_{0}+\hat{\boldsymbol{u}}_{4} r_{1} \operatorname{Sin} \beta_{2} \operatorname{Sin} \phi_{0} \\
\Rightarrow \overrightarrow{\boldsymbol{a}}=\left[\overrightarrow{\boldsymbol{r}}_{1}(\phi)-\overrightarrow{\boldsymbol{r}}_{2}(\phi)\right](\phi=0)
\end{gathered}
$$




$$
\begin{gathered}
\overrightarrow{\boldsymbol{b}}=-\hat{\boldsymbol{u}}_{1} r_{1} \operatorname{Cos} \beta_{1} \operatorname{Sin} \phi_{0}+\hat{\boldsymbol{u}}_{2}\left(r_{1} \operatorname{Cos} \beta_{2} \operatorname{Cos} \phi_{0}-r_{2}\right)-\hat{\boldsymbol{u}}_{3} r_{1} \operatorname{Sin} \beta_{1} \operatorname{Sin} \phi_{0}+\hat{\boldsymbol{u}}_{4} r_{1} \operatorname{Sin} \beta_{2} \operatorname{Cos} \phi_{0} \\
\Rightarrow \overrightarrow{\boldsymbol{b}}=\left[\overrightarrow{\boldsymbol{r}_{1}}(\phi)-\overrightarrow{\boldsymbol{r}_{2}}(\phi)\right]\left(\phi=\frac{\pi}{2}\right) \\
\overrightarrow{\boldsymbol{a}} \cdot \overrightarrow{\boldsymbol{a}}=a^{2}=r_{1}^{2}-2 r_{1} r_{2} \operatorname{Cos} \beta_{1} \operatorname{Cos} \phi_{0}+r_{2}^{2} ; \quad|\overrightarrow{\boldsymbol{a}}|=a \\
\overrightarrow{\boldsymbol{b}} \cdot \overrightarrow{\boldsymbol{b}}=b^{2}=r_{1}^{2}-2 r_{1} r_{2} \operatorname{Cos} \beta_{2} \operatorname{Cos} \phi_{0}+r_{2}^{2} \quad ; \quad|\overrightarrow{\boldsymbol{b}}|=b \\
\overrightarrow{\boldsymbol{a}} \cdot \overrightarrow{\boldsymbol{b}}=r_{1} r_{2}\left(\operatorname{Cos} \beta_{1}-\operatorname{Cos} \beta_{2}\right) \operatorname{Sin} \phi_{0}
\end{gathered}
$$

Square of the focal ${ }^{6,9}$ distance $\left(c^{2}\right)(17)$ of this vector ellipse ${ }^{6}$ can be found using (14) - (15), and its eccentricity ${ }^{6} e$ (18) can be determined using (14) - (15) and (17).

$$
\begin{gathered}
c^{2}=\left|a^{2}-b^{2}\right|=2 r_{1} r_{2}\left(\operatorname{Cos} \beta_{2}-\operatorname{Cos} \beta_{1}\right)\left|\operatorname{Cos} \phi_{0}\right| \quad(\text { Focal Distance Squared }) \\
e^{(a>b)}=\frac{c}{a}=\sqrt{\frac{2 r_{1} r_{2}\left(\operatorname{Cos} \beta_{2}-\operatorname{Cos} \beta_{1}\right)\left|\operatorname{Cos} \phi_{0}\right|}{r_{1}^{2}-2 r_{1} r_{2} \operatorname{Cos} \beta_{1} \operatorname{Cos} \phi_{0}+r_{2}^{2}}} \text { or } \quad e \stackrel{(a<b)}{=} \frac{c}{b}=\sqrt{\frac{2 r_{1} r_{2}\left(\operatorname{Cos} \beta_{2}-\operatorname{Cos} \beta_{1}\right)\left|\operatorname{Cos} \phi_{0}\right|}{r_{1}^{2}-2 r_{1} r_{2} \operatorname{Cos} \beta_{2} \operatorname{Cos} \phi_{0}+r_{2}^{2}}}
\end{gathered}
$$

Using this mathematical basis we have described through (1) - (16), the following "circular model in four dimensions" with the given parameter mappings is being proposed, to provide a simple mathematical expression for two individual economies, as well as a measure for the amount of interaction between these two international economies.

- Each economy is represented by a circle in four dimensions, namely Economy 1 and Economy 2 correspond to Circle 1 and Circle 2 in four dimensions, respectively.

- Population of Economy 1 is $p_{1}$ (19), which is used as the radius $r_{1}$ (8) of Circle 1, and the population of Economy 2 is $p_{2}(19)$, which is used as the radius $r_{2}(8)$ of Circle 2.

$$
r_{1}=p_{1} \quad ; \quad r_{2}=p_{2}
$$

- For simplicity, the start of every fiscal period is accepted to be a timestamp $t_{0}$ point when points $\mathbf{P}_{1}$ and $\mathbf{P}_{2}$ on the two circles have a phase of $\left[\phi_{1}\left(t_{0}\right)=\phi_{2}\left(t_{0}\right)=0\right]$ (2) - (3) simultaneously, hence their phase difference being $\left[\phi_{0}\left(t_{0}\right)=0\right](4)$ at time $\left(t=t_{0}=0\right)$. 
- At the end of each fiscal period $\left(t=t_{\text {fiscal }}\right)$, which is generally a fiscal year, state of Economy 1 is taken to be positioned at point $\mathbf{P}_{1}$ phased at $\phi_{1}\left(t_{\text {fiscal }}\right)$ (20) on Circle 1, and state of Economy 2 is taken to be positioned at point $\mathbf{P}_{2}$ phased at $\phi_{2}\left(t_{\text {fiscal }}\right)$ (21) on Circle 2, their phase difference at fiscal period $\left(t=t_{\text {fiscal }}\right)$ end being $\phi_{0}\left(t_{\text {fiscal }}\right)$ (22).

$$
\begin{gathered}
\phi_{1}\left(t_{\text {fiscal }}\right)=\phi+\phi_{0}=\phi_{2}\left(t_{\text {fiscal }}\right)+\phi_{0}\left(t_{\text {fiscal }}\right)=\omega_{1} t_{\text {fiscal }} \quad\left(\text { Phase of } \mathbf{P}_{1} \text { at } t=t_{\text {fiscal }}\right) \\
\left.\phi_{2}\left(t_{\text {fiscal }}\right)=\phi=\phi\left(t_{\text {fiscal }}\right)=\omega_{2} t_{\text {fiscal }} \quad \text { (Phase of } \mathbf{P}_{2} \text { at } t=t_{\text {fiscal }}\right)
\end{gathered}
$$

$\phi_{0}\left(t_{\text {fiscal }}\right)=\phi_{1}\left(t_{\text {fiscal }}\right)-\phi_{2}\left(t_{\text {fiscal }}\right)=\left(\omega_{1}-\omega_{2}\right) t_{\text {fiscal }} \quad$ (Phase difference of $\mathbf{P}_{1}$ and $\mathbf{P}_{2}$ at $\left.t=t_{\text {fiscal }}\right)$

- Gross National Income (GNI) $)^{1}$ of each economy at the end of a fiscal period $\left(t=t_{\text {fiscal }}\right)$ is taken as the area swept by the radius vector of the corresponding circle pointing at sweeping points on the given circle corresponding to that economy in four dimensions. In other words, $(G N I)_{1}(23)$ of Economy 1 is equal to area $A_{1}(23)$ swept by radius vector $\vec{r}_{1}(5)$ - (6) pointing at point $\mathbf{P}_{1}$ on Circle 1 from time $\left(t=t_{0}=0\right)$ until time $\left(t=t_{\text {fiscal }}\right)$, and $(G N I)_{2}(24)$ of Economy 2 is equal to area $A_{2}$ (24) swept by radius vector $\overrightarrow{\boldsymbol{r}}_{2}$ (7) pointing at point $\mathbf{P}_{2}$ on Circle 2 from time $\left(t=t_{0}=0\right)$ until time $\left(t=t_{\text {fiscal }}\right)$. This definition leads to an expression of $(G N I)_{1}$ (23) of Economy 1 as $k_{1}$ (23) times the area of Circle 1, which is defined in terms of the population $p_{1}$ (19) of Economy 1, and an expression of $(G N I)_{2}$ (24) of Economy 2 as $k_{2}$ (24) times the area of Circle 2, which is defined in terms of population $p_{2}$ (19) of Economy 2, for fiscal period $\left(t=t_{\text {fiscal }}\right)$, where $k_{1}$ (23) and $k_{2}(24)$ are positive real numbers. The coefficient $k_{1}$ (23) can thus be obtained using $(G N I)_{1}(23)$ and $p_{1}$ (19) values, and the coefficient $k_{2}$ (24) can be obtained using $(G N I)_{2}(24)$ and $p_{2}(19)$ values.

$$
(G N I)_{1}=A_{1}=k_{1}\left(\pi r_{1}^{2}\right)=k_{1} \pi p_{1}^{2} \quad \Rightarrow \quad k_{1}=\frac{(G N I)_{1}}{\pi r_{1}^{2}}=\frac{(G N I)_{1}}{\pi p_{1}^{2}}
$$




$$
(G N I)_{2}=A_{2}=k_{2}\left(\pi r_{2}^{2}\right)=k_{2} \pi p_{2}^{2} \quad \Rightarrow \quad k_{2}=\frac{(G N I)_{2}}{\pi r_{2}^{2}}=\frac{(G N I)_{2}}{\pi p_{2}^{2}}
$$

- Using the definitions for $(G N I)_{1}(23)$ and $(G N I)_{2}(24)$, the "GNI per capita" of the two economies, which is Gross National Income $(\mathrm{GNI})^{1}$ of each economy divided by its population, can be calculated and expressed as $(G N I p c)_{1}$ (25) for Economy 1 and $(G N I p c)_{2}$ (26) for Economy 2, for the given fiscal period.

$$
\begin{gathered}
(\text { GNIpc })_{1}=\frac{(G N I)_{1}}{p_{1}}=\frac{A_{1}}{p_{1}}=k_{1} \pi p_{1} \\
(G N I p c)_{2}=\frac{(G N I)_{2}}{p_{2}}=\frac{A_{2}}{p_{2}}=k_{2} \pi p_{2}
\end{gathered}
$$

- Based on the given definitions for $(G N I)_{1}(23)$ and $(G N I)_{2}$ (24), we can conclude that the radius vector $\overrightarrow{\boldsymbol{r}}_{1}(5)-(6)$ pointing at point $\mathbf{P}_{1}$ on Circle 1 sweeps a total angle of $\phi_{1}\left(t_{\text {fiscal }}\right)$ (27) between time $\left(t=t_{0}=0\right)$ and time $\left(t=t_{\text {fiscal }}\right), k_{1}$ (23) times traversing $(2 \pi)$ radians, and the radius vector $\overrightarrow{\boldsymbol{r}}_{2}(7)$ pointing at point $\mathbf{P}_{2}$ on Circle 2 sweeps a total angle of $\phi_{2}\left(t_{\text {fiscal }}\right)$ (28) between time $\left(t=t_{0}=0\right)$ and time $\left(t=t_{\text {fiscal }}\right), k_{2}$ (24) times traversing $(2 \pi)$ radians. This leads to the definitions in (27) - (28), from which we are able to calculate angular velocities $\omega_{1}(27)$ and $\omega_{2}$ (28), as well as frequencies $f_{1}(27)$ and $f_{2}(28)$, for the two circles corresponding to the two economies in this model.

$$
\begin{aligned}
& \phi_{1}\left(t_{\text {fiscal }}\right)=\phi+\phi_{0}=2 \pi k_{1}=\frac{2(G N I)_{1}}{p_{1}^{2}}=\omega_{1} t_{\text {fiscal }} \Rightarrow \omega_{1}=\frac{2 \pi}{T_{1}}=2 \pi f_{1}=\frac{2 \pi k_{1}}{t_{\text {fiscal }}} \Rightarrow f_{1}=\frac{1}{T_{1}}=\frac{k_{1}}{t_{\text {fiscal }}} \\
& \phi_{2}\left(t_{\text {fiscal }}\right)=\phi=2 \pi k_{2}=\frac{2(G N I)_{2}}{p_{2}^{2}}=\omega_{2} t_{\text {fiscal }} \Rightarrow \omega_{2}=\frac{2 \pi}{T_{2}}=2 \pi f_{2}=\frac{2 \pi k_{2}}{t_{\text {fiscal }}} \Rightarrow f_{2}=\frac{1}{T_{2}}=\frac{k_{2}}{t_{\text {fiscal }}}
\end{aligned}
$$

- For the given fiscal period, we take the "amount of Gross National Income (GNI) ${ }^{1}$ of Economy 1 obtained in Economy 2", defined as $(G N I)_{1,2}(29)$, to be the projection of 
$(G N I)_{1}$ (23) onto plane of Circle 2, where the angle $\beta_{1}(5)-(6)$ is the constant orbital inclination angle between Circle 1 and Circle 2 in the $\hat{\boldsymbol{u}}_{1}-\hat{\boldsymbol{u}}_{3}$ dimension plane. Similarly, for the given fiscal period, we take the "amount of Gross National Income $(\mathrm{GNI})^{1}$ of Economy 2 obtained in Economy 1", defined as $(G N I)_{2,1}(30)$, to be the projection of $(G N I)_{2}$ (24) onto plane of Circle 1, where the angle $\beta_{2}(5)-(6)$ is the constant orbital inclination angle between Circle 1 and Circle 2 in the $\hat{\boldsymbol{u}}_{2}-\hat{\boldsymbol{u}}_{4}$ dimension plane.

$(G N I)_{1,2}=(G N I)_{1} \operatorname{Cos} \beta_{1}=k_{1} \pi p_{1}^{2} \operatorname{Cos} \beta_{1}\left[\right.$ Amount of $(G N I)_{1}$ obtained in Economy 2$]$

$(G N I)_{2,1}=(G N I)_{2} \operatorname{Cos} \beta_{2}=k_{2} \pi p_{2}^{2} \operatorname{Cos} \beta_{2} \quad\left[\right.$ Amount of $(G N I)_{2}$ obtained in Economy 1]

- As a result, for the given fiscal period, the definitions in (29) - (30) would allow us to determine the values of $\beta_{1}$ (31) and $\beta_{2}$ (32) in this two-circle system in four dimensions, which we use to model the inter-relation of Economy 1 and Economy 2.

$$
\begin{aligned}
& \beta_{1}=\operatorname{Cos}^{-1}\left[\frac{(G N I)_{1,2}}{(G N I)_{1}}\right]=\operatorname{Cos}^{-1}\left[\frac{(G N I)_{1,2}}{k_{1} \pi p_{1}^{2}}\right] \Rightarrow\left\{\begin{array}{l}
\operatorname{Cos} \beta_{1}=\frac{(G N I)_{1,2}}{(G N I)_{1}} \\
\operatorname{Sin} \beta_{1}=\sqrt{1-\left[\frac{(G N I)_{1,2}}{(G N I)_{1}}\right]^{2}}
\end{array}\right. \\
& \beta_{2}=\operatorname{Cos}^{-1}\left[\frac{(G N I)_{2,1}}{(G N I)_{2}}\right]=\operatorname{Cos}^{-1}\left[\frac{(G N I)_{2,1}}{k_{2} \pi p_{2}^{2}}\right] \Rightarrow\left\{\begin{array}{l}
\operatorname{Cos} \beta_{2}=\frac{(G N I)_{2,1}}{(G N I)_{2}} \\
\operatorname{Sin} \beta_{2}=\sqrt{1-\left[\frac{(G N I)_{2,1}}{(G N I)_{2}}\right]^{2}}
\end{array}\right.
\end{aligned}
$$

- In order to express the import-export relation of the two economies for the given fiscal period, in the corresponding two-circle model in four dimensions, we define $\ell_{1 \rightarrow 2}$ as the amount of exports from Economy 1 to Economy 2, or equivalently as the amount of imports to Economy 2 from Economy 1, and we define $\ell_{2 \rightarrow 1}$ as the amount of exports from Economy 2 to Economy 1, or equivalently as amount of imports to Economy 1 from Economy 2. In vector notation, we define $\vec{\ell}$ (33) vector corresponding to $\vec{\ell}$ (9) vector 
between centers of the two circles in four-dimensions, for convenience taken to be in $\hat{\boldsymbol{u}}_{3}$ dimension only, whose magnitude $\ell$ (34) is determined by the absolute value of the difference $\left(\ell_{2 \rightarrow 1}-\ell_{1 \rightarrow 2}\right)$.

$$
\begin{aligned}
& \vec{\ell}=\hat{\boldsymbol{u}}_{3}\left(\ell_{2 \rightarrow 1}-\ell_{1 \rightarrow 2}\right) \\
& \ell=|\vec{\ell}|=\left|\ell_{2 \rightarrow 1}-\ell_{1 \rightarrow 2}\right|
\end{aligned}
$$

- As a result, based on our "two-circle model in four dimensions", the amount of interaction between Economy 1 and Economy 2 at the end of each fiscal period $\left(t=t_{\text {fiscal }}\right)$ can be measured by the distance $\overrightarrow{\boldsymbol{d}}$ (35) vector to point $\mathbf{P}_{1}$ on Circle 1 positioned at angle of $\phi_{1}\left(t_{\text {fiscal }}\right)$ (27), from point $\mathbf{P}_{2}$ on Circle 2 positioned at angle of $\phi_{2}\left(t_{\text {fiscal }}\right)$ (28), based on $\overrightarrow{\boldsymbol{d}}(\phi)$ (11). In determining $\overrightarrow{\boldsymbol{d}}$ (35), we use the value of radius vector $\overrightarrow{\boldsymbol{r}}_{1}$ (5) with magnitude $r_{1}$ (19) pointing at point $\mathbf{P}_{1}$ on Circle 1 at $\phi_{1}\left(t_{\text {fiscal }}\right)$ (27), the value of radius vector $\overrightarrow{\boldsymbol{r}}_{2}$ (7) with magnitude $r_{2}$ (19) pointing at point $\mathbf{P}_{2}$ on Circle 2 at $\phi_{2}\left(t_{f i s c a l}\right)$ (28), the $\vec{\ell}$ (33) vector from center of Circle 2 to center of Circle 1, as well as values of $\beta_{1}$ (31) and $\beta_{2}(32)$, all obtained via the known values of $p_{1}, p_{2},(G N I)_{1}$, $(G N I)_{2},(G N I)_{1,2}$, and $(G N I)_{2,1}$ at the end of each fiscal period $\left(t=t_{\text {fiscal }}\right)$ for these two international economies. The magnitude $d$ (36) of $\vec{d}$ (35) is a scalar measure for the amount of interaction between these two international economies, and calculated by taking the Dot Product ${ }^{6}$ of $\overrightarrow{\boldsymbol{d}}$ (35) vector with itself. 


$$
\begin{aligned}
& \overrightarrow{\boldsymbol{d}}=\overrightarrow{\boldsymbol{r}}_{1}\left[\phi_{1}\left(t_{\text {fiscal }}\right)\right]-\overrightarrow{\boldsymbol{r}}_{2}\left[\phi_{2}\left(t_{\text {fiscal }}\right)\right]+\vec{\ell} \\
& =\hat{\boldsymbol{u}}_{1}\left\{r_{1} \operatorname{Cos}\left[\phi_{1}\left(t_{\text {fiscal }}\right)\right] \operatorname{Cos} \beta_{1}-r_{2} \operatorname{Cos}\left[\phi_{2}\left(t_{\text {fiscal }}\right)\right]\right\} \\
& +\hat{\boldsymbol{u}}_{2}\left\{r_{1} \operatorname{Sin}\left[\phi_{1}\left(t_{\text {fiscal }}\right)\right] \operatorname{Cos} \beta_{2}-r_{2} \operatorname{Sin}\left[\phi_{2}\left(t_{\text {fiscal }}\right)\right]\right\} \\
& +\hat{\boldsymbol{u}}_{3}\left\{r_{1} \operatorname{Cos}\left[\phi_{1}\left(t_{\text {fiscal }}\right)\right] \operatorname{Sin} \beta_{1}+\left(\ell_{2 \rightarrow 1}-\ell_{1 \rightarrow 2}\right)\right\} \\
& +\hat{\boldsymbol{u}}_{4} r_{1} \operatorname{Sin}\left[\phi_{1}\left(t_{\text {fiscal }}\right)\right] \operatorname{Sin} \beta_{2} \\
& =\hat{\boldsymbol{u}}_{1}\left\{p_{1} \frac{(G N I)_{1,2}}{(G N I)_{1}} \operatorname{Cos}\left[\frac{2(G N I)_{1}}{p_{1}^{2}}\right]-p_{2} \operatorname{Cos}\left[\frac{2(G N I)_{2}}{p_{2}^{2}}\right]\right\} \\
& +\hat{\boldsymbol{u}}_{2}\left\{p_{1} \frac{(G N I)_{2,1}}{(G N I)_{2}} \operatorname{Sin}\left[\frac{2(G N I)_{1}}{p_{1}^{2}}\right]-p_{2} \operatorname{Sin}\left[\frac{2(G N I)_{2}}{p_{2}^{2}}\right]\right\} \\
& +\hat{\boldsymbol{u}}_{3}\left\{p_{1} \sqrt{1-\left[\frac{(G N I)_{1,2}}{(G N I)_{1}}\right]^{2}} \operatorname{Cos}\left[\frac{2(G N I)_{1}}{p_{1}^{2}}\right]+\left(\ell_{2 \rightarrow 1}-\ell_{1 \rightarrow 2}\right)\right\} \\
& +\hat{\boldsymbol{u}}_{4} p_{1} \sqrt{1-\left[\frac{(G N I)_{2,1}}{(G N I)_{2}}\right]^{2}} \operatorname{Sin}\left[\frac{2(G N I)_{1}}{p_{1}^{2}}\right]
\end{aligned}
$$

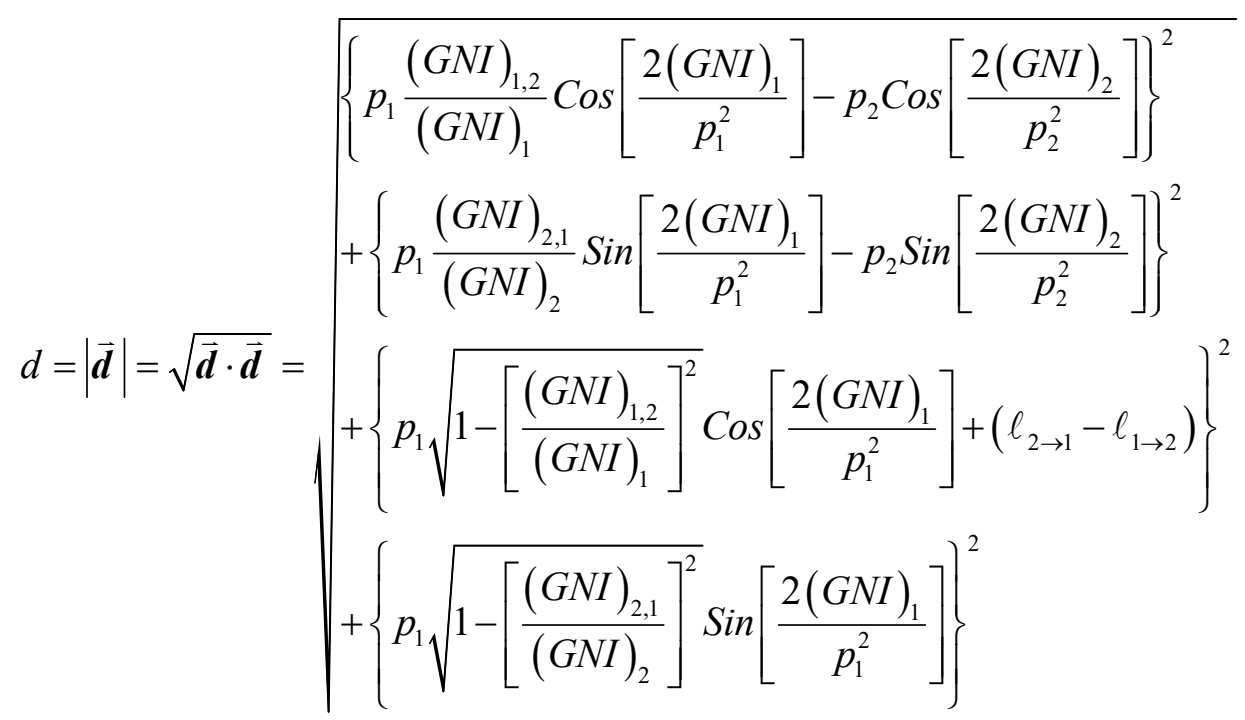

- Having determined the scalar radii $r_{1}$ (19) and $r_{2}$ (19) based on populations $p_{1}$ and $p_{2}$ of the two economies, respectively, as well as the angular velocities $\omega_{1}(27)$ and $\omega_{2}(28)$ for the given fiscal period between time $\left(t=t_{0}=0\right)$ and time $\left(t=t_{f i s c a l}\right)$, we can also 
calculate the "specific energy" (37) - (38) of each economy in terms of "kinetic energy per mass" as in physics, as a measure for the "energy density ${ }^{11 "}$ " (37) - (38) of each economy, providing a means for comparison of income capacities of Economy 1 (37) and Economy 2 (38) in terms of $(\text { GNIpc })_{1}(25)$ and $(\text { GNIpc })_{2}$ (26), respectively. Here, we use $\left(E=\frac{1}{2} m v^{2}\right)$ for kinetic energy of each economy system, where $m$ is taken as the virtual mass and $(v=r \omega)$ as the velocity of the system. As a result, the ratio of Gross National Income $(\mathrm{GNI})^{1}$ of each economy to its population at the end of each fiscal period $\left(t=t_{\text {fiscal }}\right)$, namely "GNI per capita" 3 ", provides a measure for the income capacity of that economy, for comparison with other international economies. Further, we understand that twice the "GNI per capita" of an economy is analogous to the velocity $v$ of an economy for a unit fiscal period, such as a fiscal year, in this circular model in four dimensions that we use.

$$
\begin{gathered}
\omega_{1}=\frac{2(G N I)_{1}}{t_{\text {fiscal }} p_{1}^{2}} \Rightarrow v_{1}=r_{1} \omega_{1}=\frac{2(G N I)_{1}}{t_{\text {fiscal }} p_{1}} \Rightarrow \frac{E_{1}\left(t_{\text {fiscal }}\right)}{m_{1}}=\frac{\left(\frac{1}{2} m_{1} v_{1}^{2}\right)}{m_{1}}=\frac{1}{2} v_{1}^{2}=\frac{2(G N I)_{1}^{2}}{t_{\text {fiscal }}^{2} p_{1}^{2}}=\frac{2(G N I p c)_{1}^{2}}{t_{\text {fiscal }}^{2}} \\
\omega_{2}=\frac{2(G N I)_{2}}{t_{\text {fiscal }} p_{2}^{2}} \Rightarrow v_{2}=r_{2} \omega_{2}=\frac{2(G N I)_{2}}{t_{\text {fiscal }} p_{2}} \Rightarrow \frac{E_{2}\left(t_{\text {fiscal }}\right)}{m_{2}}=\frac{\left(\frac{1}{2} m_{2} v_{2}^{2}\right)}{m_{2}}=\frac{1}{2} v_{2}^{2}=\frac{2(G N I)_{2}^{2}}{t_{\text {fiscal }}^{2} p_{2}^{2}}=\frac{2(G N I p c)_{2}^{2}}{t_{\text {fiscal }}^{2}}(38
\end{gathered}
$$

- Based on definitions of $\phi_{0}(4), \beta_{1}$ (31), and $\beta_{2}$ (32) above, the magnitudes $a$ (14) and $b(15)$ of the semi-major ${ }^{7}$ and semi-minor ${ }^{7}$ axis vectors of the vector ellipse ${ }^{6}$ formed between the two circles in four-dimensions become $a$ (39) and $b$ (40), respectively, whereas the Dot $\operatorname{Product}^{8}(\overrightarrow{\boldsymbol{a}} \cdot \overrightarrow{\boldsymbol{b}})$ (16) of vectors $\overrightarrow{\boldsymbol{a}}$ (12) and $\overrightarrow{\boldsymbol{b}}$ (13) becomes $(\overrightarrow{\boldsymbol{a}} \cdot \overrightarrow{\boldsymbol{b}})$ (41). Comparing $a$ (39) and $b$ (40), based on $\beta_{1}$ (31) and $\beta_{2}$ (32) defined above in terms of $(G N I)_{1,2}(29)$ and $(G N I)_{2,1}(30)$, we can reach the conclusion that the semi-major ${ }^{7}$ and semi-minor ${ }^{7}$ axis magnitudes provide a measure for comparing the amounts of Gross National Income $(\mathrm{GNI})^{1}$ of each economy obtained in the other economy. In other words, 
if the ratio $\left[\frac{(G N I)_{1,2}}{(G N I)_{1}}\right](31)$, which is the portion of "amount of Gross National Income $(\mathrm{GNI})^{1}$ of Economy 1 obtained in Economy 2 " within total $(G N I)_{1}(23)$ of Economy 1, is greater than the ratio $\left[\frac{(G N I)_{2,1}}{(G N I)_{2}}\right](32)$, which is the portion of "amount of Gross National Income $(\mathrm{GNI})^{1}$ of Economy 2 obtained in Economy 1" within total $(G N I)_{2}$ (24) of Economy 2, in this fiscal period, $a$ (39) becomes semi-minor ${ }^{7}$ axis magnitude and $b(40)$ becomes semi-major ${ }^{7}$ axis magnitude of the virtual ellipse formed by the two circle system in four-dimensions representing these two economies, or vice versa. Therefore, comparing the semi-major ${ }^{7}$ and semi-minor ${ }^{7}$ axis magnitudes of the vector ellipse ${ }^{6}$ formed between the two circles in four-dimensions corresponding to our two international economies, one can determine which economy benefits more from the other economy in a given fiscal period. Further, the $\operatorname{Dot}_{\operatorname{Product}^{8}}(\overrightarrow{\boldsymbol{a}} \cdot \overrightarrow{\boldsymbol{b}})(41)$ of semi-major $^{7}$ and semi-minor ${ }^{7}$ axis vectors $\overrightarrow{\boldsymbol{a}}$ (12) and $\overrightarrow{\boldsymbol{b}}$ (13), or equivalently their projection onto each other, reveals the gap between the amount of benefit each of these two economies obtains from the other. More explicitly, the greater the Dot $\operatorname{Product}^{8}(\overrightarrow{\boldsymbol{a}} \cdot \overrightarrow{\boldsymbol{b}})(41)$, the more is the gap between the amount of benefit each of these two economies obtains from the other, or equivalently, one economy obtains more benefit from the other economy.

$$
\begin{aligned}
& a=\sqrt{r_{1}^{2}-2 r_{1} r_{2} \operatorname{Cos} \beta_{1} \operatorname{Cos} \phi_{0}+r_{2}^{2}}=\sqrt{r_{1}^{2}-2 r_{1} r_{2} \frac{(G N I)_{1,2}}{(G N I)_{1}} \operatorname{Cos}\left(\frac{(G N I)_{1}}{\pi p_{1}^{2}}-\frac{(G N I)_{2}}{\pi p_{2}^{2}}\right)+r_{2}^{2}} \\
& b=\sqrt{r_{1}^{2}-2 r_{1} r_{2} \operatorname{Cos} \beta_{2} \operatorname{Cos} \phi_{0}+r_{2}^{2}}=\sqrt{r_{1}^{2}-2 r_{1} r_{2} \frac{(G N I)_{2,1}}{(G N I)_{2}} \operatorname{Cos}\left(\frac{(G N I)_{1}}{\pi p_{1}^{2}}-\frac{(G N I)_{2}}{\pi p_{2}^{2}}\right)+r_{2}^{2}} \\
& \overrightarrow{\boldsymbol{a}} \cdot \overrightarrow{\boldsymbol{b}}=r_{1} r_{2}\left(\operatorname{Cos} \beta_{1}-\operatorname{Cos} \beta_{2}\right) \operatorname{Sin} \phi_{0}=r_{1} r_{2}\left[\frac{(G N I)_{1,2}}{(G N I)_{1}}-\frac{(G N I)_{2,1}}{(G N I)_{2}}\right] \operatorname{Sin}\left(\frac{(G N I)_{1}}{\pi p_{1}^{2}}-\frac{(G N I)_{2}}{\pi p_{2}^{2}}\right)
\end{aligned}
$$


- Similarly, focal ${ }^{6,9}$ distance $c$ (42) of this vector ellipse ${ }^{6}$ can be obtained using $\left(c^{2}\right)(17)$, and its eccentricity ${ }^{6} e$ (43) can be determined using $e$ (18), again utilizing the definitions of $\phi_{0}$ (4), $\beta_{1}$ (31), and $\beta_{2}$ (32) above. Subsequently, from the focal ${ }^{6,9}$ distance $c$ (42) of the vector ellipse formed by the two circle system in four-dimensions representing these two economies, one can infer the gap between the amount of benefit each of these two economies obtains from the other, similar to what the Dot $\operatorname{Product}^{8}(\overrightarrow{\boldsymbol{a}} \cdot \overrightarrow{\boldsymbol{b}})$ (41) reveals. The eccentricity ${ }^{6} e(43)$ of the vector ellipse between the two circles in four-dimensions representing these two economies also provides a ratio which is greater when this benefit gap is bigger, and vice versa.

$$
\begin{gathered}
c=\sqrt{2 r_{1} r_{2}\left(\operatorname{Cos} \beta_{2}-\operatorname{Cos} \beta_{1}\right)\left|\operatorname{Cos} \phi_{0}\right|}=\sqrt{2 r_{1} r_{2}\left[\frac{(G N I)_{2,1}}{(G N I)_{2}}-\frac{(G N I)_{1,2}}{(G N I)_{1}}\right]\left|\operatorname{Cos}\left(\frac{(G N I)_{1}}{\pi p_{1}^{2}}-\frac{(G N I)_{2}}{\pi p_{2}^{2}}\right)\right|} \\
e=\left\{\begin{array}{l}
\frac{c^{(a>b)}}{a}=\sqrt{\frac{2 r_{1} r_{2}\left(\operatorname{Cos} \beta_{2}-\operatorname{Cos} \beta_{1}\right)\left|\operatorname{Cos} \phi_{0}\right|}{r_{1}^{2}-2 r_{1} r_{2} \operatorname{Cos} \beta_{1} \operatorname{Cos} \phi_{0}+r_{2}^{2}}}=\sqrt{\frac{2 r_{1} r_{2}\left[\frac{(G N I)_{2,1}}{(G N I)_{2}}-\frac{(G N I)_{1,2}}{(G N I)_{1}}\right]\left|\operatorname{Cos}\left(\frac{(G N I)_{1}}{\pi p_{1}^{2}}-\frac{(G N I)_{2}}{\pi p_{2}^{2}}\right)\right|}{r_{1}^{2}-2 r_{1} r_{2} \frac{(G N I)_{1,2}}{(G N I)_{1}} \operatorname{Cos}\left(\frac{(G N I)_{1}}{\pi p_{1}^{2}}-\frac{(G N I)_{2}}{\pi p_{2}^{2}}\right)+r_{2}^{2}}} \\
\frac{c}{b}=\sqrt{\frac{2 r_{1} r_{2}\left(\operatorname{Cos} \beta_{2}-\operatorname{Cos} \beta_{1}\right)\left|\operatorname{Cos} \phi_{0}\right|}{r_{1}^{2}-2 r_{1} r_{2} \operatorname{Cos} \beta_{2} \operatorname{Cos} \phi_{0}+r_{2}^{2}}}=\sqrt{\frac{2 r_{1} r_{2}\left[\frac{(G N I)_{2,1}}{(G N I)_{2}}-\frac{(G N I)_{1,2}}{(G N I)_{1}}\right]\left|\operatorname{Cos}\left(\frac{(G N I)_{1}}{\pi p_{1}^{2}}-\frac{(G N I)_{2}}{\pi p_{2}^{2}}\right)\right|}{r_{1}^{2}-2 r_{1} r_{2} \frac{(G N I)_{2,1}}{(G N I)_{2}} \operatorname{Cos}\left(\frac{(G N I)_{1}}{\pi p_{1}^{2}}-\frac{(G N I)_{2}}{\pi p_{2}^{2}}\right)+r_{2}^{2}}}
\end{array}\right.
\end{gathered}
$$




\section{CONCLUSIONS}

In this Article, a method is provided as a measure for the amount of interaction between two international economies, which are two countries or economic zones, by modelling each economy in terms of a "circle in four dimensions". Based on this method, the proximity of the two economies at the end of each fiscal period, which is generally a fiscal year, is then measured by the distance between points at the end of the given period on the two circles in four dimensions, associated with these two economies in our model. The radius of the circle corresponding to each economy is taken to be the population of the economy, whereas the Gross National Income $(\mathrm{GNI})^{1}$ of each economy at the end of a fiscal period is taken as the area swept by the radius vector of the corresponding circle for the given economy. For every fiscal period, the portion of Gross National Income (GNI) $)^{1}$ of each economy obtained in the other economy is used to determine the orbital inclination angles between the circles corresponding to these two economies in our model. Further, the import-export relations between these two economies are used to determine the distance between the centers of the corresponding circles of the two economies. As a consequence, angular velocities and frequencies of the two-economy system are determined, leading to an understanding that twice the "GNI per capita" 3 " of an economy is analogous to the velocity of that economy for a unit fiscal period, such as a fiscal year, in this circular model in four dimensions that we use, whose square provides a measure for the income capacity of each economy in terms of "energy density ${ }^{11}$ " of the system, for comparison. Moreover, comparing the semi-major ${ }^{7}$ and semi-minor ${ }^{7}$ axis magnitudes of the vector ellipse ${ }^{6}$ formed by two circles in four-dimensions corresponding to our two international economies, one can determine which economy benefits more from the other economy in a given fiscal period, the economy corresponding to the semi-minor ${ }^{7}$ axis being the one that relatively benefits more. The focal ${ }^{6,9}$ distance of the virtual ellipse formed by the two circles in four-dimensions corresponding to our two international economies, as well as the projection of its semi-major ${ }^{7}$ and semi-minor ${ }^{7}$ axis vectors, reveal the gap between the amount of benefit each of these two economies obtains from the other. Eccentricity ${ }^{6}$ of the vector ellipse between the two circles in four-dimensions representing these two economies also provides a ratio which is greater when this benefit gap is bigger, and vice versa. 


\title{
AUTHOR CONTRIBUTIONS
}

Aslı Pinar Tan is the only author contributing to this Article.

\section{DATA AVAILIBILITY}

Data sharing is not applicable to this article as no data were created or analyzed in this study.

\section{DECLARATION OF INTEREST STATEMENT}

The Author declares that there is no conflict of interest.

\section{KEYWORDS}

GNI, GDP, GNIpc, International Economy, Export, Import, Circle, Model

\begin{abstract}
ABOUT THE AUTHOR
Aslı Pınar Tan's findings in this Article are part of all her findings as a result of her personal theoretical studies and research over the years independent from any institution or university, which she has published in the book "Everyhing Is A Circle: A New Model For Orbits Of Bodies In The Universe" ${ }^{4}$, and will further publish in a set of books and other articles. She is an Electrical \& Electronics Engineer, Bsc. 1995 and Msc. 1997 graduated from Bilkent University, Ankara, Turkey, and she also holds a degree in Multi-Disciplinary Space Studies program graduated in 2000 from International Space University, Strasbourg, France. She has worked professionally more than 20 years in the Global ICT / Telecom industry, in addition to her academic career in Electromagnetics and Space Applications, all independent from this research. She has been granted a Young Scientist Award by URSI (Union Radio Science Internationale) in 1998 based on her Master Thesis Research results presenting a systematic methodology for High-Frequency Radar Antenna Design using the Genetic Algorithm and Equivalent Edge Currents, to generate plain waves in the near field, which is utilized in the industry since then. (For more: http://www.linkedin.com/in/apinartan)
\end{abstract}




\section{REFERENCES}

References in this Article can be any Economy and Calculus textbook, as the economical definitions and mathematical equations and identities used as a basis are all currently accepted in existing textbooks.

1. Gross national income, OECD Data, https://data.oecd.org/natincome/gross-national-income.htm, (2021)

2. Gross domestic product (GDP), OECD Data, https://data.oecd.org/gdp/gross-domestic-product-gdp.htm, (2021)

3. List of countries by GNI (nominal) per capita, Wikipedia, http://en.wikipedia.org/wiki/List_of_countries_by_GNI_(nominal)_per_capita, (2021)

4. Tan, A.P., Everything is a Circle: A New Model For Orbits of Bodies in the Universe, Amazon Kindle Publishing, 2020, ISBN \& EAN 979-8-56-757466-9

Paperback Book: https://www.amazon.com/gp/product/B08NYG14X8

Kindle eBook: https://www.amazon.com/gp/product/B08PVS2FBW

5. Tan, A.P. Distance Between Two Circles In Any Number Of Dimensions Is A Vector Ellipse, Preprints 2021, 2021040632 (doi: 10.20944/preprints202104.0632.v1)

6. Ellipse, Wikipedia, http://en.wikipedia.org/wiki/Ellipse (2021)

7. Semi-major and semi-minor axes, Wikipedia, http://en.wikipedia.org/wiki/Semi-major_and_semi-min3or_axes (2021)

8. Dot product, Wikipedia, https://en.wikipedia.org/wiki/Dot_product, (2021)

9. Focus (geometry), Wikipedia, http://en.wikipedia.org/wiki/Focus_geometry) (2021)

10. Specific energy, Wikipedia, https://en.wikipedia.org/wiki/Specific energy, (2021)

11. Energy density, Wikipedia, https://en.wikipedia.org/wiki/Energy density, (2021) 